\title{
Quantitative Analysis of Southern rice black-streaked dwarf virus in Sogatella furcifera and Virus Threshold for Transmission
}

\author{
Keiichiro Matsukura, Tomomi Towata, Kazuhiro Yoshida, Junichi Sakai, Mitsuru Okuda, \\ Masatoshi Onuki and Masaya Matsumura
}

First to seventh authors: NARO Kyushu Okinawa Agricultural Research Center, Suya 2421, Koshi, Kumamoto 861-1192, Japan; and sixth author: NARO Agricultural Research Center, 3-1-1 Kannondai, Tsukuba, Ibaraki 305-8666, Japan.

Accepted for publication 7 October 2014.

\begin{abstract}
Matsukura, K., Towata, T., Yoshida, K., Sakai, J., Okuda, M., Onuki, M., and Matsumura, M. 2015. Quantitative analysis of southern rice blackstreaked dwarf virus in Sogatella furcifera and virus threshold for transmission. Phytopathology 105:550-554.

We investigated Southern rice black-streaked dwarf virus (SRBSDV) accumulation in a vector insect, the whitebacked planthopper (Sogatella furcifera), to elucidate the association of virus accumulation in the vector with virus transmission efficiency. Real-time quantitative reverse transcription polymerase chain reaction analysis confirmed that this virus is transmitted in a persistent-propagative manner. SRBSDV was successfully transmitted by $S$. furcifera males in which RNA accumulation of the capsid
\end{abstract}

ABSTRAC

The Southern rice black-streaked dwarf virus (SRBSDV) is a recently reported member of the genus Fijivirus (family Reoviridae) (10), causing seriously stunted growth of plants and twisted leaf tips in rice, Oryza sativa $(4,6,29)$. This virus disease was initially recorded in Guangdong province, China, in 2001, and was later reported in an extensive area of Southern China (29), large areas in the Red River Delta of Vietnam $(4,6)$, and the southern part of Japan $(13,16)$. The rapid expansion of the SRBSDV-affected area was caused by long-distance migration of vector insects, whitebacked planthoppers (Sogatella furcifera) (16), and perhaps small brown planthoppers (Laodelphax striatellus) (29).

The infection cycle of SRBSDV has been well documented. Both S. furcifera adults and nymphs can acquire SRBSDV by feeding for as little as $5 \mathrm{~min}$ on diseased rice (20). The inoculation access period for a high probability of transmission is generally 3 days $(6,29)$, but the virus can be transmitted in as little as 30 min feeding by viruliferous $S$. furcifera (20). The latent period in the $S$. furcifera nymph varies from 6 to 14 days (20). Most viruliferous adult S. furcifera intermittently transmit SRBSDV at intervals of 2 to 6 days, but some individuals can continuously transmit the virus throughout the rest of their life (20). SRBSDV infects not only rice but also other poaceous crops such as maize (Zea mays), in which it causes serious stunting of growth $(26,31)$, barnyard millet (Echinochloa crusgalli), and sorghum (Sorghum bicolor) $(11,31)$. Typical symptoms of infection (i.e., stunted growth and twisted leaf tips) are usually observed approximately 20 days after virus infection (13). S. furcifera can acquire SRBSDV even from latently infected rice (13).

$S$. furcifera seems to transmit SRBSDV in a persistentpropagative manner (7). SRBSDV acquired by $S$. furcifera initially

Corresponding author: K. Matsukura; E-mail address: mtkr@affrc.go.jp

http://dx.doi.org/10.1094/PHYTO-05-14-0142-R

(C) 2015 The American Phytopathological Society protein gene of SRBSDV was $>10^{3}$ in the whole body of S. furcifera, indicating that the threshold accumulation of the virus RNA for virus transmission is $10^{3}$ in an S. furcifera male. The SRBSDV detection rate in the immigrant population of S. furcifera was high in 2011 (39.5\%); however, most of the insects contained fewer than $10^{3}$ RNAs of the capsid protein gene. This result indicates that the risk of SRBSDV epidemics could be estimated from the proportion of virus-transmissible $S$. furcifera (i.e., $S$. furcifera that contained more than $10^{3}$ RNAs of the virus capsid protein gene) rather than the SRBSDV detection rate in $S$. furcifera.

Additional keywords: overseas immigration, reovirus, stunted growth, viral disease. enters the epithelial cells of the midgut, and then replicates and spreads within the alimentary canal, and finally reaches the salivary gland and is transmitted to plants during feeding by the vector (9). SRBSDV replication has also been observed in the midgut of L. striatellus; however, unlike in $S$. furcifera, SRBSDV does not move to the salivary glands of L. striatellus (8).

SRBSDV does not complete its year-long infection cycle in southern Japan, which is the current northern boundary of SRBSDV distribution. S. furcifera cannot overwinter in this region because of a lack of rice plants, which is its exclusive host during winter. Also, plant hosts of SRBSDV (e.g., rice, barnyard millet, maize, sorghum) are not available during the winter. The absence of both vector and host plants in winter results in the disappearance of SRBSDV in the southern part of Japan, indicating that the occurrence of SRBSDV in this area is mainly caused by immigration of viruliferous $S$. furcifera from China in early summer. Determining the SRBSDV transmission efficiency in the immigrant population of $S$. furcifera is therefore important for predicting SRBSDV occurrence in southern Japan.

Recent development of quantification techniques for plant viruses represented by real-time quantitative reverse transcriptionpolymerase chain reaction (RT-qPCR) has permitted elucidation of changes in the level of virus accumulation in the vector body. For example, Raspberry latent virus transmitted by the large raspberry aphid, Amphorophora agathonica, replicates 6.3- to 24-fold in the aphid body during the first 10 days after virus acquisition, and the degree of virus replication varies widely among individual aphids (21). The transmission frequency of Tomato spotted wilt virus (TSWV) by the western flower thrips, Frankliniella occidentalis, is positively related to the amount of TSWV in the thrips (22). These quantitative analyses can help improve control strategies for plant viruses.

In this study, we examined the accumulation of SRBSDV in $S$. furcifera using RT-qPCR to reveal the correlation between virus accumulation and transmission efficiency. We also discuss an 
approach to predicting the risk of immigrant population of $S$. furcifera as a vector of SRBSDV from overseas.

\section{MATERIALS AND METHODS}

Insects. Stock cultures of $S$. furcifera originally collected from Koshi, Kumamoto, Japan $\left(32.87^{\circ} \mathrm{N}, 130.74^{\circ} \mathrm{E}\right)$, in June 2010 were used for laboratory experiments. They were mass-reared using rice seedlings (variety 'Reiho') at $25^{\circ} \mathrm{C}$ and 16 -h light and 8-h dark photoperiod as described in a previous report (15).

Virus strain. The virus strain used was originally collected from Amakusa, Kumamoto $\left(32.33^{\circ} \mathrm{N}, 130.12^{\circ} \mathrm{E}\right)$, in September 2010 and was kept in a greenhouse under the following protocol. $S$. furcifera nymphs were released on mature (posttillering stage) SRBSDV-infected rice (variety 'TN1'). After approximately 2 weeks, when the released nymphs molted to adults, three adult males were transferred to a young rice plant (at the second or third leaf stage). This is an efficient method for transmitting SRBSDV from a mature plant to a new one with a high success rate (more than $80 \%$ ).

Determination of SRBSDV accumulation in S. furcifera. SRBSDV accumulation in the salivary glands and the rest of the insect body was individually determined using RT-qPCR. After dissection of a $S$. furcifera salivary gland under the microscope, total RNA in the salivary gland and other body parts were separately extracted using TriPure Isolation Reagent (Roche Diagnostics Co., Ltd., Tokyo) and suspended in $25 \mu \mathrm{l}$ of distilled water. To exclude DNA from the sample solution, $1 \mu$ l of RNase-free DNase (Promega, WI) was added, followed by incubation at $37^{\circ} \mathrm{C}$ for $30 \mathrm{~min}$.

RT-qPCR was conducted with a LightCycler 480FLM (Roche Diagnostics Co., Ltd.) using the Takara One Step SYBR PrimeScript RT-PCR kit (Takara Bio Co. Ltd., Shiga). Thermal conditions in RT-qPCR were the same as those described by Matsukura et al. (13). This quantification method determines the amount of RNA, which is commonly used as an indicator of virus accumulation in dsRNA virus $(2,17,30)$. The number of RNA of target region in individual adults was calculated with an absolute quantification method after calibration using reference gene expression as described below.

The primer set of Matsukura et al. (13) (forward: 5'-GAG CGG AGT CTC CTC ATT TA-3', reverse: 5' -GCA ACG ATG AAC CTT TCT CT- $3^{\prime}$ ) was used for amplification of the capsid protein gene of SRBSDV. cDNA with the T7 RNA polymerase promoter-binding domain was amplified from total RNA extracted from viruliferous $S$. furcifera with RT-PCR using the PrimeScript One Step RT-PCR Kit Ver.2 (Takara Bio Co. Ltd.). After purification of the RT-PCR product using the Amicon Ultra Centrifugal Filter (30K) (Merck Millipore Ltd., MA), the target region was transcribed using the in vitro Transcription T7 kit (Takara Bio Co. Ltd.). After purification of RNA with RNase-free DNase followed by isopropanol precipitation, the concentration of RNA in the solution was determined with a spectrophotometer. Using the standard RNA solution, we preliminary confirmed that the efficiency of the RT-qPCR for the capsid protein gene of SRBSDV was $102.7 \%$ in a range of cycle threshold $(\mathrm{Ct})$ from approximately 11 to 30 (Fig. 1); therefore, all quantification analyses of SRBSDV were performed within this range.

We compared expression stability among five reference genes in $S$. furcifera (Table 1). Gene expression of mitochondrial cytochrome oxidase subunit I (COI) (primers designed from GenBank sequence, accession no. AF222884), glutathione $s$-transferase S1 (GSTS) (JQ917480), glutathione $s$-transferase E1 (GSTE) (JQ917482), argonaute 2 (Ago2) (JX023535), and actin (AY192151) was examined by RT-qPCR in two pairs of adult $S$. furcifer $a$ at each of $1,4,7$, and 10 days after emergence (i.e., 16 adults were used in total). We had previously confirmed that these primer sets specifically amplify their target regions in $S$. furcifera. Efficiencies of RT-qPCR obtained by each primer set were determined using dilution series of extract RNA.
Effect of feeding duration on SRBSDV accumulation in S. furcifera. We examined the relationship between the SRBSDV acquisition access period (i.e., the duration of $S$. furcifera feeding on diseased rice) and SRBSDV accumulation in the insect body. One hundred virus-free $S$. furcifera adults were released on SRBSDVinfected rice (variety 'TN1') at the tillering stage, and then 8 to 16 adults were sampled individually at $0.5,1,2,4,7$, and 10 days after release. Amounts of RNA of the capsid protein gene of SRBSDV in the salivary gland and the rest of the body were determined using RT-qPCR. The experiment was conducted using both male and female $S$. furcifera.

SRBSDV transmission efficiency in adult males and females $S$. furcifera. Both male and female adults of $S$. furcifera were kept on SRBSDV-infected rice at the tillering stage for 7 days to allow them to acquire SRBSDV. Viruliferous adults were then transferred individually to young, virus-free rice plants and kept for $1,3,5$, and 7 days. After removal of the $S$. furcifera, the rice seedlings were kept in a greenhouse and, 32 days after the initial introduction of viruliferous insects to the experimental plants, the plants were examined for SRBSDV infection. The appearance of twisted leaf tips was used as an indicator of viral infection. There were 15 to 40 replicates for each treatment (two sexes, four feeding durations).

Correlation between the amount of SRBSDV in adult males and transmission efficiency. Adult males of $S$. furcifera were allowed to acquire the virus by being exposed to SRBSDVinfected rice at the tillering stage for 1 day. They were then moved to uninfected rice seedlings for 5 days to let SRBSDV replicate in the insects. These viruliferous males were then released individually on young rice plants for 1 day. Surviving insects $(n=236)$ were removed from the plants and the amount of RNA of the capsid protein gene of SRBSDV in the whole insects was immediately determined using RT-qPCR. The young rice plants associated with those surviving insects were kept in a greenhouse for 28 days before being examined for SRBSDV infection. Adult females were not used in this experiment because we previously observed that adult females sometimes kill rice plants through their oviposition behavior and produce large numbers of nymphs, which can transmit SRBSDV (20).

Determination of SRBSDV accumulation in immigrant populations of $S$. furcifera in Japan. SRBSDV numbers and transmission ability were analyzed in S. furcifera that had immigrated from China to Japan. We observed large numbers of immigrating S. furcifera on 5 July 2011, 2 July 2012, and 11 July 2012 in Koshi, Kumamoto, Japan $\left(32.87^{\circ} \mathrm{N}, 130.74^{\circ} \mathrm{E}\right)$. Individuals immigrating on 5 July 2011 and 2 July 2012 were collected from rice paddies on the day they were first observed. On 11 July 2012 we could not distinguish new immigrants from those that had arrived on

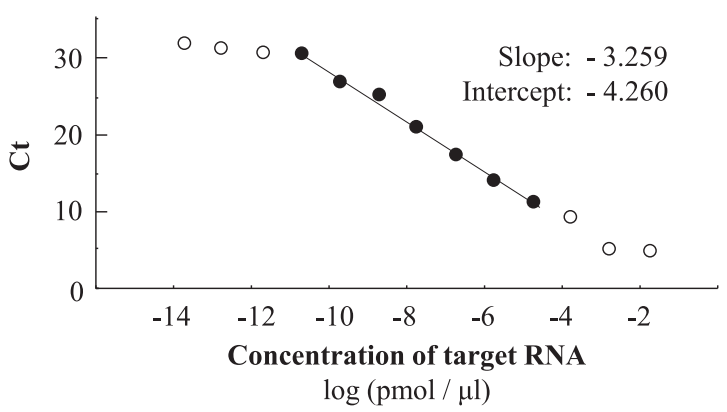

Fig. 1. Calibration curve for real-time quantitative reverse transcription polymerase chain reaction amplification of standard RNA of the capsid protein gene of Southern rice black-streaked dwarf virus (SRBSDV). A 10-fold dilution series of standard RNA solution was used as template. An appropriate amplification efficiency $(102.7 \%)$ was observed in a range of cycle threshold (Ct) from approximately 11 to 30 . Slope and intercept of calibration curve were obtained from data within this range (shown with closed circle) 
2 July 2012. Therefore, on 12 July 2012 we collected insects from a grass lawn. Immigrant individuals landing on grass either immediately die or migrate to rice fields, so adult $S$. furcifera on the grass lawn collected on 12 July 2012 were regarded as having arrived from China on 11 July 2012.

The adults collected on 5 July 2011 were immediately used for SRBSDV quantification. Those from 2 and 11 July 2012 were maintained individually on young rice plants for 7 days, after which RNA accumulation of SRBSDV in the whole body of each individual was determined using RT-qPCR. The young rice plants were kept in a greenhouse for approximately 2 months before being examined by RT-PCR for SRBSDV infection.

Statistical analyses. Stability of the reference gene expression was examined using BestKeeper (19). A reference gene that showed the lowest standard deviation of the $\mathrm{Ct}$ value was selected as the most stable gene. The effects of sex and feeding duration on SRBSDV accumulation were examined separately in the salivary gland and the rest of the body by two-way analysis of variance (twoway ANOVA) and compared among different feeding durations by multiple comparison using Tukey's honestly significant difference (HSD) test. SRBSDV transmission rates were compared between sexes and among feeding durations by multiple comparison for proportions (27). The association between SRBSDV accumulation in $S$. furcifera males and virus transmission efficiency was examined by $\chi^{2}$ test followed by residual analysis after categorizing of SRBSDV accumulation on a $\log _{10}$ scale $<10^{1}$ to $>10^{8}$ (e.g., $S$. furcifera in the $10^{4}$ category contained from $10^{4}$ to $<10^{5}$ copies of SRBSDV).

\section{RESULTS}

Selection of reference gene. All five primer sets for the reference genes used for RT-qPCR amplified the target fragments with efficiencies of 92.5 to $108.2 \%$ (Table 1). RT-qPCR for the actin gene exhibited the lowest standard deviation of $\mathrm{Ct}$ value (Table 1), so we used this gene as the reference gene in this study.

Changes in SRBSDV accumulation in $S$. furcifera. Amount of the virus RNA in the salivary gland (two-way ANOVA, $F=35.46, \mathrm{df}=5, P<0.001)$ and the rest of the body $(F=46.31$, $\mathrm{df}=5, P<0.001)$ was significantly affected by duration of feeding on SRBSDV-infected rice. Sex had no significant effect on the virus RNA accumulation in either the salivary gland $(F=0.05, \mathrm{df}=1$, $P=0.828)$ or the rest of the body $(F=1.26$, df $=1, P=0.262)$. Interaction between feeding duration and sex was significant for the rest of the body $(F=5.02, \mathrm{df}=5, P<0.001)$ but not for the salivary gland $(F=1.46, \mathrm{df}=5, P=0.205)$. Level of the virus RNA began to increase in both the salivary gland and the rest of the body 1 day after the start of exposure to diseased rice (Fig. 2). Statistically, the virus RNA accumulation in the rest of the body reached a maximum by day 2 , and that in the salivary gland reached a maximum by days 7 and 4 for males and females, respectively. Virus RNA titers in the rest of the body remained high until day 10, whereas there was a continuous decrease of the virus RNA accumulation after day 4 in the whole body in male.
SRBSDV transmission efficiency by male and female adults of $\boldsymbol{S}$. furcifera. SRBSDV transmission efficiency was significantly affected by inoculation access period (Table 2 ). The transmission efficiency of males and females increased from 20 to $87.5 \%$ and from 0 to $80 \%$, respectively, with increased feeding duration from 1 to 7 days. Males and females showed a similar trend of increasing SRBSDV transmission efficiency with longer feeding duration; however, $65 \%$ of males transmitted SRBSDV by day 3 of feeding on rice plants, whereas no virus transmission was observed in females at the same time point.

Effect of SRBSDV accumulation in $\boldsymbol{S}$. furcifera males on virus transmission. The virus RNA accumulation in $S$. furcifera at the sixth day after virus acquisition varied from $<10^{1}$ (copies of SRBSDV/whole insects) to $>10^{8}$ (Fig. 3). SRBSDV transmission efficiency was significantly affected by the virus RNA accumulation $\left(\chi^{2}\right.$ test, $\chi^{2}=41.10$, df $\left.=7, P<0.001\right)$. SRBSDV was transmitted by males containing $>10^{3}$ of the virus RNA, whereas there was no virus transmission by males containing $<10^{2}$ of the virus RNA. SRBSDV transmission was observed at all levels of the virus RNA accumulation from $10^{3}$ to $>10^{8}$, although males

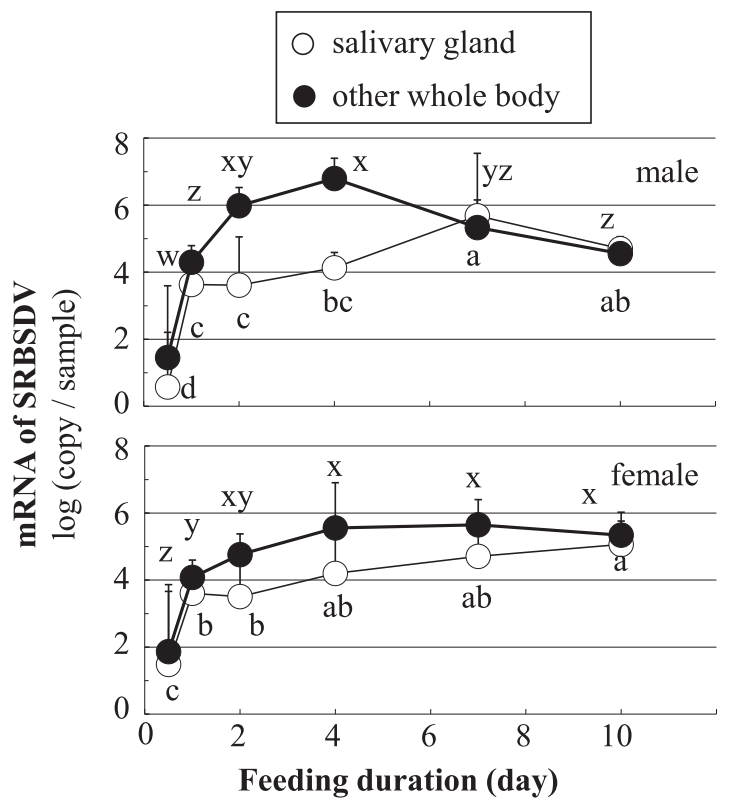

Fig. 2. The relationship between feeding duration of adult Sogatella furcifera on Southern rice black-streaked dwarf virus (SRBSDV)-infected rice and virus accumulation in the salivary gland and the rest of the body. Number of copies of the capsid protein RNA of SRBSDV in each sample was determined by realtime quantitative reverse transcription polymerase chain reaction after calibration by amount of actin gene expression. Number of replicates was usually 16 and occasionally 8 for each treatment. Same letters (a to d, x to w) indicate no significant difference in average virus accumulation among different feeding durations within the same sex (Tukey's HSD test after log transformation, $\alpha=0.05$ ).

TABLE 1. Primer sequences for reference genes of Sogatella furcifera and standard deviation of cycle threshold (Ct) value obtained by real-time quantitative reverse transcription polymerase chain reaction (RT-qPCR) using each primer set

\begin{tabular}{|c|c|c|c|}
\hline Reference gene & Sequences & Efficiency of RT-qPCR (\%) & Standard deviation of $\mathrm{Ct}$ (min-max) \\
\hline COI & F: 5'-GGTAAACGTGAAACCTTTGG-3' & 92.5 & $1.13(8.52-12.89)$ \\
\hline GSTS & $\begin{array}{l}\text { R: 5'-CGCTGAAGTAAAGTACGCTC-3' } \\
\text { F: 5'-GCCATCTCCAGGTACTTTGG-3' } \\
\text { R: 5'-AGAACGGTATGGTCGTTTCG-3' }\end{array}$ & 107.3 & $1.75(15.15-21.48)$ \\
\hline GSTE & $\begin{array}{l}\text { F: 5'-ACAGTCATGCAATCAACGCG-3' } \\
\text { R: } 5^{\prime} \text {-AACATCGCACTCCATGTGTG-3' }\end{array}$ & 108.2 & $1.43(21.75-26.47)$ \\
\hline Ago2 & $\begin{array}{l}\text { F: 5'-CTACAGTTCCCCTATCTGCC-3' } \\
\text { R: } 5^{\prime} \text {-GCTTGGCAGCATTCTTGACC-3' }\end{array}$ & 102.5 & $1.01(17.32-22.19)$ \\
\hline
\end{tabular}


containing $10^{4}$ and $10^{5}$ copies transmitted virus at significantly higher rates than the others (residual analysis, $\alpha=0.05$ ).

SRBSDV accumulation in immigrant $\boldsymbol{S}$. furcifera. We collected 81, 196, and 166 adult immigrants of $S$. furcifera on 5 July 2011, 2 July 2012, and 11 July 2012, respectively (Table 3). SRBSDV was detected in 17 of 38 males and 15 of 43 females of the 5 July 2011 immigrants, with most containing $10^{1}$ to $10^{2}$ SRBSDV RNA. A small number of adults collected on 2 July 2012 (5 of 196) and 11 July 2012 (3 of 166) had SRBSDV; no SRBSDV transmission by the immigrants on 2 and 11 July was observed.

\section{DISCUSSION}

SRBSDV accumulated in both male and female adults of S. furcifera as the acquisition access period increased (Fig. 2). Like most persistent-propagative viruses $(1,7,8)$, SRBSDV acquired from rice by $S$. furcifera replicates in viroplasm in the midgut cells and then moves through the hemolymph to the salivary glands to transfer to new host plants upon feeding of the vectors (9). Our analysis demonstrated that accumulation of the virus RNA in salivary gland and the rest of the body reached a maximum, respectively, between days 4 to 7 and at day 2 after the beginning of feeding on diseased plants, suggesting that SRBSDV acquired by $S$. furcifera begins to multiply within the first 2 days in the midgut cells, and moves to the salivary gland over the next 2 to 5 days. The observed increase and retention of SRBSDV in the bodies of the vector confirmed that this virus is transmitted in a persistentpropagative manner, consistent with previous studies $(8,12,24)$.

The maximum virus accumulation in the salivary gland at days 4 to 7 (Fig. 2) indicates that $S$. furcifera can develop transmissible level of SRBSDV after 4 to 7 days of latent period. Pu et al. (20) reported that the latent period of SRBSDV in $S$. furcifera ranged

TABLE 2. Transmission efficiency of Southern rice black-streaked dwarf virus in adult males and females of Sogatella furcifera $^{\mathrm{z}}$

\begin{tabular}{lcccc}
\hline \multirow{2}{*}{$\begin{array}{l}\text { Inoculation } \\
\text { access period } \\
\text { (day) }\end{array}$} & \multicolumn{2}{c}{ Male } & & Female \\
\cline { 2 - 3 } \cline { 5 - 5 } & $n$ & $\begin{array}{c}\text { Transmission } \\
\text { rate }(\%)\end{array}$ & & $\begin{array}{c}\text { Transmission } \\
\text { rate }(\%)\end{array}$ \\
\hline 1 & 20 & $20 \mathrm{bc}$ & 20 & $0 \mathrm{c}$ \\
3 & 20 & $65 \mathrm{ab}$ & 20 & $0 \mathrm{c}$ \\
5 & 20 & $70 \mathrm{a}$ & 20 & $65 \mathrm{ab}$ \\
7 & 40 & $87.5 \mathrm{a}$ & 15 & $80 \mathrm{a}$ \\
\hline
\end{tabular}

$\mathrm{z}$ Values followed by the same letter indicate no significant difference in transmission rate (multiple comparison for proportion, $\alpha=0.05$ ).

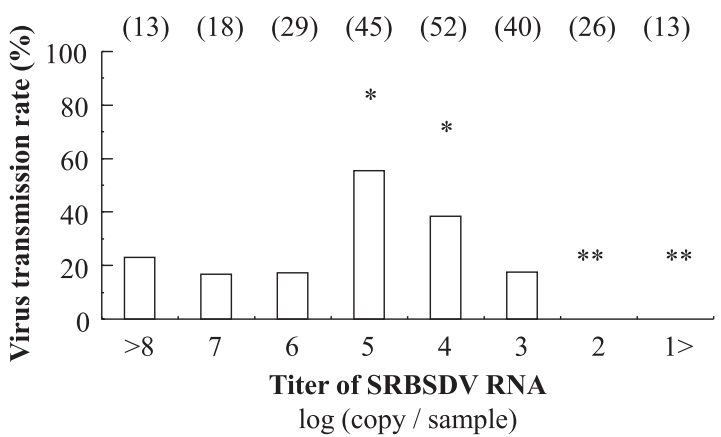

Fig. 3. Effect of virus accumulation in the whole body of Sogatella furcifera on virus transmission rate. Data were analyzed after categorizing the number of the capsid protein RNA of Southern rice black-streaked dwarf virus (SRBSDV) in individual adults into each order from $<10^{1}$ to $>10^{8}$ (e.g., $S$. furcifera at an order of $10^{4}$ contained from $10^{4}$ to $<10^{5}$ of the virus RNA). Numbers in parentheses above each bar represent the number of S. furcifera in each virus accumulation. $*$ and $* *$ indicate that virus transmission rate was significantly higher $(*)$ or lower $(* *)$ than the expected value (residual analysis, $\alpha=0.05)$. from 6 to 14 days. The difference in the results of the two studies might be caused by their different experimental designs. Pu et al. (20) used third and fourth instar nymphs as vectors whereas we used adults. Also, Pu et al. (20) replaced the rice plants every 2 days in order to determine the first day that $S$. furcifera transmitted SRBSDV to host plants. Their experimental design was reasonable as an initial attempt to reveal SRBSDV dynamics in the vector; however, it could not address the effect of continuous infestation by viruliferous $S$. furcifera on successful virus transmission. Our experiment showed that only $20 \%$ of viruliferous adult males could transmit SRBSDV following one day of feeding on rice plants, and viruliferous adult females could not transmit SRBSDV even after infestation for 3 days (Table 2). The latent period proposed by $\mathrm{Pu}$ et al. (20) might be shortened if more than 2-day infestation by viruliferous $S$. furcifera was considered. Assuming that $S$. furcifera can transmit SRBSDV when the salivary gland is saturated with the virus, the latent period of SRBSDV in adult $S$. furcifera is estimated as 4 to 7 days.

Quantification of SRBSDV accumulation in S. furcifera identified a clear threshold titer on the order of $10^{3}\left(10^{3}\right.$ to $<10^{4}$ virus RNA/whole insects) for adult males to be able to transmit the virus. SRBSDV was not transmitted by $S$. furcifera with a virus accumulation of $<10^{3}$ (Fig. 3). Although a threshold titer in the salivary gland could be more informative regarding the mechanism of virus transmission from vector to plant because virus in the salivary gland is injected into the plants during the feeding activity of the insects, the threshold per whole body may be a useful measure to guide SRBSDV management in the field.

Above the threshold of the virus RNA accumulation, no correlation was found between virus accumulation and transmission rate (Fig. 3). A previous study demonstrated a positive correlation between virus (TSWV) density in the vector and transmission efficiency (22). SRBSDV, however, did not show such a positive correlation. On the contrary, $S$. furcifera containing higher accumulation of the virus RNA (above $10^{6}$ ) resulted in lower virus transmission rates than those containing $10^{4}$ and $10^{5}$ (Fig. 3). Virus acquisition sometimes has a negative impact on vector insects $(5,23)$. Excessive accumulation of SRBSDV might result in a lower virus transmission rate because of lower viability (leading to lower feeding activity) of $S$. furcifera.

Assuming a threshold SRBSDV transmission level of $>10^{3}$ for adult males, the $S$. furcifera immigrating from China to southern Japan in 2011 and 2012 had few transmitting individuals. The three immigrant populations in 2011 and 2012 included 1.0 to $2.6 \%$ transmissible males (Table 3). Although a threshold is unknown for females, the immigrants would include only a low number of viruliferous females because females containing $>10^{3}$ levels of the virus RNA were rare (Table 3). This low percentage of transmissible adults did not pose a serious risk of SRBSDV epidemics in rice in 2011 and 2012 in southern Japan (K. Matsukura and M. Matsumura, unpublished data).

In predicting the occurrence of insect-borne viral diseases in the field, the frequency of virus-carrying insects is often used instead of the actual transmissible ratio $(3,28)$. Our results showed that the risk of

TABLE 3. Southern rice black-streaked dwarf virus (SRBSDV) accumulation in Sogatella furcifera immigrants from China to Japan

\begin{tabular}{llrrrr}
\hline & & & \multicolumn{3}{c}{$\begin{array}{c}\text { SRBSDV RNA } \\
\text { accumulation }\end{array}$} \\
\cline { 3 - 6 } Estimated migration date & Sex & $n$ & $>10^{3}$ & $10^{2}$ & Negative \\
\hline 5 July 2011 & Male & 38 & 1 & 16 & 21 \\
& Female & 43 & 0 & 15 & 28 \\
2 July 2012 & Male & 102 & 1 & 0 & 101 \\
& Female & 94 & 1 & 3 & 90 \\
11 July 2012 & Male & 95 & 1 & 0 & 94 \\
& Female & 71 & 2 & 0 & 69 \\
\hline
\end{tabular}

$\mathrm{z}$ The accumulation is the number of RNA copies of the capsid protein gene of SRBSDV in a whole body of $S$. furcifera. 
infection may have been overestimated in such surveys because the proportion of transmissible vectors among virus-carrying insects might be far lower. Among the 2010 immigrants, SRBSDV was detected in $39.5 \%$ of adults; however, most of these contained the virus RNA at the order of $10^{2}\left(10^{2}\right.$ to $\left.10^{3}\right)$. These adults would not immediately transmit SRBSDV to rice, although virus amplification in S. furcifera after immigration should be considered. In this case, we would estimate the risk of SRBSDV epidemics to be low (no or very little SRBSDV damage was recorded in 2010) despite the high SRBSDV detection rate among the immigrants. Such discordance between virus detection rate and virulence of vector was also observed in the transmission of Chrysanthemum stem necrosis virus by F. occidentalis (18).

Evaluating the threshold level for SRBSDV accumulation in $S$. furcifera for virus transmission would contribute to a more precise forecasting of SRBSDV occurrence, particularly in the southern part of Japan. Quantification of SRBSDV in field populations of $S$. furcifera with RT-qPCR is not a practical method because qPCR analysis is expensive. Adjustment of detection sensitivity of a reasonable detection method such as RT-PCR and enzyme-linked immunosorbent assay for specific detection of viruliferous $S$. furcifera should be considered for practical use. Clarification of variation in transmission efficiency among vector populations and virus strains is another subject for better forecasting of SRBSDV occurrence. The transmission efficiency of SRBSDV by $S$. furcifera would not be highly differentiated at this stage because this novel virus has much lower nucleotide diversities than other closely related virus (25) and genetic diversity of S. furcifera in Asia is low due to its long-distance migration (14). Nevertheless, continuous monitoring of virulence and infectious capacity is important to prevent further outbreaks of this virus.

\section{ACKNOWLEDGMENTS}

We thank Kayoko Abe and Reiko Yamada for preparation of insects for our experiments. We also thank Prof. Robert Cowie in University of Hawaii for grammatical editing our manuscript. This study was supported by research and development projects for application in promoting new policy of agriculture, forestry, and fisheries (23034) from the Ministry of Agriculture, Forestry, and Fisheries of Japan.

\section{LITERATURE CITED}

1. Ammar, El-D., Gargani, D., Lett, J. M., and Peterschmitt, M. 2009. Large accumulation of Maize streak virus in the filter chamber and midgut cells of the leafhopper vector Cicadulina mbila. Arch. Virol. 154:255-262.

2. Bachanek-Bankowska, K., Maan, S., Castillo-Olivares, J., Manning, N. M., Maan, N. S., Potgieter, A. C., Nardo, A. D., Sutton, G., Batten, C., and Mertens, P. P. C. 2014. Real time RT-PCR assays for detection and typing of African horse sickness virus. PLoS ONE 9:e93758.

3. Boonham, N., Smith, P., Walsh, K., Tame, J., Morris, J., Spence, N., Bennison, J., and Barker, I. 2002. The detection of Tomato spotted wilt virus (TSWV) in individual thrips using real time fluorescent RT-PCR (TaqMan). J. Virol. Methods 101:37-48.

4. Cuong, H. V., Hai, N. V., Man, V. T., and Matsumoto, M. 2009. Rice dwarf disease in North Vietnam in 2009 is cause by southern rice black-streaked dwarf virus (SRBSDV). Bull. Inst. Trop. Agric. Kyushu Univ. 32:85-92.

5. Donaldson, J. R., and Gratton, C. 2007. Antagonistic effects of soybean viruses on soybean aphid performance. Environ. Entomol. 36:918-925.

6. Hoang, A. T., Zhang, H. M., Yang, J., Chen, J. P., Hébrard, E., Zhou, G. H., Vinh, V. N., and Cheng, J. A. 2011. Identification, characterization, and distribution of Southern rice black-streaked dwarf virus in Vietnam. Plant Dis. 95:1063-1069.

7. Hogenhout, S. A., Ammar, El-D., Whitfield, A. E., and Redinbaugh, M. G. 2008. Insect vector interactions with persistently transmitted viruses. Annu. Rev. Phytopathol. 46:327-359.

8. Jia, D., Chen, H., Mao, Q., Liu, Q., and Wei, T. 2012. Restriction of viral dissemination from the midgut determines incompetence of small brown planthopper as a vector of Southern rice black-streaked dwarf virus. Virus Res. 167:404-408.

9. Jia, D., Chen, H., Zheng, A., Chen, Q., Liu, Q., Xie, L., Wu, Z., and Wei, T. 2012. Development of an insect vector cell culture and RNA interference system to investigate the functional role of fijivirus replication protein. J. Virol. 86:5800-5807.
10. King, A. M. Q., Adams, M. J., Carstens, E. B., and Lefkowits, E. J. 2012. Page 1327 in: Virus Taxonomy: Classification and Nomenclature of Viruses. Academic Press, UK.

11. Li, Y. Z., Cao, Y., Zhou, Q., Guo, H. M., and Ou, G. C. 2012. The efficiency of Southern rice black-streaked dwarf virus transmission by the vector Sogatella furcifera to different host plant species. J. Integr. Agr. 11: 621-627.

12. Liu, Y., Jia, D., Chen, H., Chen, Q., Xie, L., Wu, Z., and Wei, Y. 2011. The P7-1 protein of Southern rice black-streaked dwarf virus, a fijivirus, induces the formation of tubular structures in insect cells. Arch. Virol. 156:1729-1736.

13. Matsukura, K., Towata, T., Sakai, J., Onuki, M., Okuda, M., and Matsumura, M. 2013. Dynamics of Southern rice black-streaked dwarf virus in rice and implication for virus acquisition. Phytopathology 103: 509-512.

14. Matsumoto, Y., Matsumura, M., Sanada-Morimura, S., Hirai, Y., Sato, Y., and Noda, H. 2013. Mitochondrial cox sequences of Nilaparvata lugens and Sogatella furcifera (Hemiptera, Delphacidae): Low specificity among Asian planthopper populations. Bull. Entomol. Res. 103:382-392.

15. Matsumura, M., Takeuchi, H., Satoh, M., Sanada-Morimura, S., Otuka, A., Watanabe, T., and Thanh, D. V. 2008. Species-specific insecticide resistance to imidacloprid and fipronil in the rice planthoppers and Sogatella furcifera in East and South-east Asia. Pest Manag. Sci. 64: 1115-1121.

16. Matsumura, M., and Sakai, J. 2011. Occurrence of new disease caused by Southern rice black-streaked dwarf virus transmitted by the whitebacked planthopper. Plant Prot. 65:46-48. (in Japanese)

17. Mijatovic-Rustempasic, S., Tam, K. I., Kerin, T. K., Lewis, J. M., Gautam, R., Quaye, O., Gentsch, J. R., and Bowen, M. D. 2013. Sensitive and specific quantitative detection of Rotavirus A by one-step real-time reverse transcription-PCR assay without antecedent double-stranded-RNA denaturation. J. Clin. Microbiol. 51:3047-3054.

18. Okuda, S., Okuda, M., Matsuura, S., Okazaki, S., and Iwai, H. 2013. Competence of Frankliniella occidentalis and Frankliniella intonsa strains as vectors for Chrysanthemum stem necrosis virus. Eur. J. Plant Pathol. 136:355-362.

19. Pfaffl, M. W., Tichopád, A., Prgomet, C., and Neuvians, T. P. 2004. Determination of stable housekeeping genes, differentially regulated target genes and sample integrity: BestKeeper-Excel-based tool using pair-wise correlations. Biotechnol. Lett. 26:509-515.

20. Pu, L., Xie, G., Ji, C., Ling, B., Zhang, M., Xu, D., and Zhou, G. 2012. Transmission characteristics of Southern rice black-streaked dwarf virus by rice planthoppers. Crop Prot. 41:71-76.

21. Quito-Avila, D. F., Lightle, D., Lee, J., and Martin, R. R. 2012. Transmission biology of Raspberry latent virus, the first aphid-borne reovirus. Phytopathology 102:547-553.

22. Rotenberg, D., Kumar, N. K. K., Ullman, D. E., Montero-Astúa, M., Willis, D. K., German, T. L., and Whitfield, A. E. 2009. Variation in Tomato spotted wilt virus titer in Frankliniella occidentalis and its association with frequency of transmission. Phytopathology 99:404-410.

23. Rubinstein, G., and Czosnek, H. 1997. Long-term association of Tomato yellow leaf curl virus with its whitefly vector Bemisia tabaci: Effect on the insect transmission capacity, longevity and fecundity. J. Gen. Virol. 78: 2683-2689.

24. Xu, Y., Zhou, W., Zhou, Y., Wu, J., and Zhou, X. 2012. Transcriptome and comparative gene expression analysis of Sogatella furcifera (Horváth) in response to Southern rice black-streaked dwarf virus. PLoS ONE 7: e36238.

25. Xue, J., Li, J., Zhang, H., Yang, J., Lv, M., Gao, B., and Chen, J. 2014. Molecular characterization of Southern rice blacked-streaked dwarf virus (SRBSDV) from Vietnam. J. Phytopathol. 162:349-358.

26. Yin, X., Xu, F., Zheng, F., Li, X., Liu, B., and Zhang, C. 2011. Molecular characterization of segment S7 to S10 of a southern rice black-streaked dwarf virus isolate from maize in northern China. Virol. Sin. 26:47-53.

27. Zar, J. H. 1996. Biostatistical Analysis. 3rd Ed. Prentice-Hall, Upper Saddle River, NJ.

28. Zhang, X., Zhou, G., and Wang, X. 2010. Detection of Wheat dwarf virus (WDV) in wheat and vector leafhopper (Psammotettix alienus Dahlb.) by real-time PCR. J. Virol. Methods 169:416-419.

29. Zhou, G., Wen, J., Cai, D., Li, P., Xu, D., and Zhang, S. 2008. Southern rice black-streaked dwarf virus: A new proposed Fijivirus species in the family Reoviridae. Chin. Sci. Bull. 53:3677-3685.

30. Zhou, T., Du, L., Lan, Y., Sun, F., Fan, Y., and Zhou, Y. 2014. Development of SYBR Green I-based one-step real time RT-PCR assay for quantifying Southern rice black-streaked dwarf virus in rice. J. Phytopathol. 162:26-32.

31. Zhu, J., Zhou, Q., Cui, Y., and Gao, B. D. 2012. New natural host of Southern rice black-streaked dwarf virus. J. Hunan Agric. Univ. 38:58-60. (in Chinese with English summary) 